\title{
Fat-Free Mass Depletion Is Associated With Poor Exercise Capacity Irrespective of Dynamic Hyperinflation in COPD Patients
}

\author{
Elisabetta Teopompi PhD, Panagiota Tzani PhD, Marina Aiello PhD, Sara Ramponi MD, \\ Francesco Andrani MD, Emilio Marangio MD, Enrico Clini MD, and Alfredo Chetta MD
}

\begin{abstract}
BACKGROUND: In patients with COPD, we investigated the effect of the fat-free mass (FFM) on maximal exercise capacity and the relationship with changes in operational lung volumes during exercise. METHODS: In a cross-sectional study 57 patients $(16$ females; age $65 \pm 8$ y) were consecutively assessed by resting lung function, symptom-limited cardiopulmonary exercise test, and body composition by means of bioelectrical impedance analysis to measure the FFM index (FFMI; in kilograms per square meter). RESULTS: Patients were categorized as depleted $(n=14)$ or nondepleted $(n=43)$ according to FFMI. No significant difference in gender, age, and resting lung function was found between depleted and nondepleted patients. When compared with nondepleted COPD patients, the depleted COPD patients had a significantly lower $\mathrm{O}_{2}$ uptake at the peak of exercise and at anaerobic threshold as well as at peak oxygen pulse, oxygen uptake efficiency slope (OUES), and heart rate recovery (HRR) $(P<.05$ for all comparisons), but similar inspiratory capacity/total lung capacity at the peak of exercise. Moreover, they also reported significantly higher leg fatigue $(P<.05)$, but not dyspnea on exertion. In all patients, significant correlations $(P<.01)$ were found between FFMI and peak oxygen pulse, OUES, HRR, and leg fatigue. CONCLUSIONS: This study shows that FFM depletion plays a part in the reduction of exercise capacity in COPD patients, regardless of dynamic hyperinflation, and is strictly associated with poor cardiovascular response to exercise and to leg fatigue, but not with dyspnea. Key words: fat-free mass; dynamic hyperinflation; exercise; cardiac function; COPD. [Respir Care 2014;59(5):718-725. (C) 2014 Daedalus Enterprises]
\end{abstract}

\section{Introduction}

Patients with COPD commonly exhibit impaired exercise capacity. In these patients, the decreased physical activity does not seem to depend merely on resting lung

\footnotetext{
Drs Teopompi, Tzani, Aiello, Ramponi, Andrani, Marangio, and Chetta are affiliated with Clinical \& Experimental Medicine, Respiratory Disease and Lung Function Unit, University of Parma, Parma, Italy. Dr Clini is affiliated with the Department of Oncology, Haematology, Respiratory Diseases, and Ospedale Villa Pineta di Gaiato, Pavullo (MO), University of Modena-Reggio Emilia, Modena, Italy.
}

The authors have disclosed no conflicts of interest.

Correspondence: Dr Elisabetta Teopompi, Unità di Malattie Respiratorie e Funzionalità Polmonare, Dipartimento di Medicina Clinica e Sperimentale, Università di Parma, Padiglione Rasori, Via G Rasori, 10, 43100 Parma, Italy. E-mail: elisabettateopompi@ymail.com.

DOI: $10.4187 /$ respcare.02709 function. The relationship between $\mathrm{FEV}_{1}$ and daily physical activities in COPD patients is very modest, ${ }^{1}$ and other factors are considered important in contributing to stagnation. On the one hand, the development of dynamic hyperinflation plays an important role in limiting exercise capacity $^{2}$ and may explain the reduction in the patient's daily physical activities, regardless of the severity of the COPD. ${ }^{3}$ Indeed, these subjects breathe in before achieving a full exhalation and, as a consequence, trap air within the lungs with each further breath, with serious mechanical and sensory repercussions. ${ }^{4}$ Furthermore, the ventilatory constraints occurring during exercise have the potential for significant negative effects on cardiovascular function. ${ }^{5,6}$

Additionally, a fat-free mass (FFM) depletion commonly occurs in COPD patients, resulting from several factors, such as systemic inflammatory mediators, disuse atrophy, poor nutrition, and oral corticosteroid medication. ${ }^{7}$ Importantly, the reduction in FFM may also contribute to impairment of exercise capacity in these patients. Earlier 
studies ${ }^{8-10}$ have reported a significant correlation between body weight and maximal exercise capacity in COPD patients. Notably, the FFM was found to be strictly related both to submaximal ${ }^{11}$ and maximal ${ }^{12}$ exercise performance in these patients.

Compared with nondepleted patients, a blunted ventilatory response at maximal exercise was found in depleted COPD patients, ${ }^{10,12}$ thereby suggesting a greater degree of dynamic hyperinflation in these patients. However, in these studies ${ }^{10,12}$ the end-expiratory lung volume was not measured during exercise, and thus the involvement of dynamic hyperinflation in the ventilatory constraints was only speculative.

We hypothesized that the depletion of lean body mass may reduce exercise capacity independently of dynamic hyperinflation during exertion. Therefore, the purpose of this study was to investigate in a cohort of patients with COPD the effect of FFM on maximal exercise capacity and the relationship with changes in operational lung volumes during maximal effort.

\section{Methods}

\section{Patients}

We enrolled patients affected by COPD, as defined according to the Global Initiative for Chronic Obstructive Lung Disease criteria, ${ }^{13}$ who were consecutively admitted to a pulmonary rehabilitation program. Eligibility criteria were as follows: (1) stable clinical condition (exacerbation free for at least 4 weeks); (2) no oxygen therapy; (3) absence of any comorbidity affecting exercise performance (anemia, neuromuscular disorders, chronic cardiac failure, malignancies, or obesity); (4) ability to perform a symptom-limited cycle ergometry cardiopulmonary exercise test (CPET) with a peak of respiratory exchange ratio of $\geq 1.05$ to exclude poor motivation; and (5) CPET stopped for muscle fatigue and/or dyspnea. All the procedures and their risks were explained to the patients, who gave their written informed consent to enter the study. The protocol was approved by the ethical committee of the University Hospital of Parma (Clinical Trial Registration Number 36215; November 12, 2010). All participants' data were analyzed and reported anonymously. No extramural funding was used to support the study.

\section{Lung Function}

Pulmonary function tests were performed according to international recommendations. ${ }^{14,15}$ A flow-sensing spirometer and a body plethysmograph connected to a computer for data analysis (Vmax 22 and 6200, SensorMedics, Yorba Linda, California) were used for the measurements. Vital capacity (VC), $\mathrm{FEV}_{1}$, FVC, forced expiratory flow

\section{QUICK LOOK}

\section{Current knowledge}

Dynamic hyperinflation in COPD is a major cause of exertional dyspnea. A number of other factors also limit exercise tolerance, including comorbid conditions and body mass index.

\section{What this paper contributes to our knowledge}

Fat-free mass depletion plays a part in the reduction of exercise capacity in patients with COPD. This is seen regardless of the degree of dynamic hyperinflation and is associated with poor cardiovascular response to exercise and leg fatigue, but not to dyspnea.

measured at $50 \%$ of $\mathrm{FVC}\left(\mathrm{FEF}_{50}\right.$; measured in liters per second), and forced inspiratory flow measured at $50 \%$ of $\mathrm{FVC}\left(\mathrm{FIF}_{50}\right.$; measured in liters per second) were recorded. $\mathrm{FEV}_{1} / \mathrm{VC}$ and $\mathrm{FEF}_{50} / \mathrm{FIF}_{50}$ were taken as indices of airway obstruction and airway collapsibility, respectively.

Thoracic gas volume was measured by body plethysmography with the subject panting against a closed shutter at a frequency slightly $<1 \mathrm{~Hz}$ and their cheeks supported by their hands. Total lung capacity (TLC) was obtained as the sum of thoracic gas volume and linked inspiratory capacity (IC). IC/TLC was taken as an index of hyperinflation of the lung. At least 3 measurements were made for each spirometry and lung volume variable to ensure reproducibility, and the highest value was used in subsequent calculations. The flow sensor was calibrated before each test using a 3-L syringe.

Lung diffusing capacity for carbon monoxide $\left(\mathrm{D}_{\mathrm{LCO}}\right)$ was measured by the single-breath method using a mixture of carbon monoxide and methane; this measurement was performed at least in duplicate. TLC, VC, IC, $\mathrm{FEV}_{1}$, and $\mathrm{D}_{\mathrm{LCO}}$ were expressed as a percentage of the predicted values, which were obtained from regression equations by Quanjer et al ${ }^{16}$ and Cotes et al. ${ }^{17}$

\section{CPET}

CPET was performed according to a standardized procedure. ${ }^{18}$ After calibrating the oxygen and carbon dioxide analyzers and flow mass sensor, patients were asked to sit on an electromagnetically braked cycle ergometer (Corival PB, Lobe Bv, Groningen, Netherlands) and the saddle was adjusted properly to avoid the maximal extension of the knee. The exercise protocol involved an initial $3 \mathrm{~min}$ of rest, followed by unloaded cycling for another $3 \mathrm{~min}$ with an increment every minute of 5-15 watts, according to the patient's anthropometry findings and the degree of func- 
tional impairment, to achieve an exercise time of between 8 and $12 \mathrm{~min}$. Patients were asked to maintain a pedaling frequency of 60 rotations/min indicated by a digital display placed on the monitor of the ergometer. Breath-bybreath oxygen uptake $\left(\dot{\mathrm{V}}_{\mathrm{O}_{2}}\right.$; in $\left.\mathrm{L} / \mathrm{min}\right)$, carbon dioxide production $\left(\dot{\mathrm{V}}_{\mathrm{CO}_{2}}\right.$; in $\left.\mathrm{L} / \mathrm{min}\right)$, tidal volume $\left(\mathrm{V}_{\mathrm{T}}\right.$; in $\left.\mathrm{L}\right)$, and minute ventilation $\left(\dot{\mathrm{V}}_{\mathrm{E}}\right.$; in $\left.\mathrm{L} / \mathrm{min}\right)$ were collected during the test (CPX/D, Med Graphics, St. Paul, Minnesota). Patients were continuously monitored using a 12-lead electrocardiogram (Welch Allyn CardioPerfect, Delft, Netherlands) and a pulse oximeter (Pulse Oximeter 8600, Nonin Medical, Plymouth, Minnesota). Blood pressure was measured at 2-min intervals. Stopping criteria consisted of symptoms such as unsustainable dyspnea or leg fatigue, chest pain, an electrocardiogram showing significant ST segment depression, or a drop in systolic blood pressure or arterial oxygen saturation of $\leq 84 \%$.

Peak work load and peak $\dot{\mathrm{V}}_{\mathrm{O}_{2}}$ were recorded as the mean value in watts and $\dot{\mathrm{V}}_{\mathrm{O}_{2}}$ during the last $20 \mathrm{~s}$ of the test. Peak $\dot{\mathrm{V}}_{\mathrm{O}_{2}}$ was expressed as an absolute value in $\mathrm{mL} / \mathrm{min}$. Anaerobic threshold (AT) was noninvasively determined by both V-slope and ventilatory equivalents methods ("dual-method approach"), because the respiratory exchange ratio approximated $1.0,{ }^{18}$ and was expressed as an absolute value in $\mathrm{mL} / \mathrm{min}$. The ventilatory response to exercise was calculated as a linear regression function by plotting $\dot{\mathrm{V}}_{\mathrm{E}}$ against $\dot{\mathrm{V}}_{\mathrm{CO}_{2}}$ obtained every 10 s during exercise $\left(\dot{\mathrm{V}}_{\mathrm{E}} / \dot{\mathrm{V}}_{\mathrm{CO}_{2}}\right.$ slope).

Changes in operational lung volumes were assessed every 2 min during exercise and at peak exercise, taking the IC measured at rest as the baseline. After a full explanation to each patient of the procedure, satisfactory technique and reproducibility of IC maneuvers were established during an initial practice session at rest. Assuming that TLC remains constant during exercise in COPD patients, ${ }^{19}$ changes in IC reflect changes in end-expiratory lung volume. Accordingly, dynamic hyperinflation can be defined as a decline in the IC greater than zero. ${ }^{20}$

The cardiovascular response of the exercise was expressed by the following parameters: oxygen pulse $\left(\mathrm{O}_{2}\right.$ pulse), $\dot{\mathrm{V}}_{\mathrm{O}_{2}}$ efficiency slope (OUES), and heart rate recovery (HRR). $\mathrm{O}_{2}$ pulse (in $\mathrm{mL} / \mathrm{beats} / \mathrm{min}$ ) was calculated by dividing instantaneous $\dot{\mathrm{V}}_{\mathrm{O}_{2}}$ by the heart rate ${ }^{18}$ and was recorded at the peak of exercise. The OUES describes the relationship between $\dot{\mathrm{V}}_{\mathrm{O}_{2}}$ and $\dot{\mathrm{V}}_{\mathrm{E}}$ during incremental exercise via a $\log$ transformation of $\dot{V}_{\mathrm{E}}$ and was expressed in $\mathrm{L} / \mathrm{min}$ as the gradient of the linear relationship of $\log _{10} \dot{\mathrm{V}}_{\mathrm{E}}$ to $\dot{\mathrm{V}}_{\mathrm{O}_{2}}{ }^{21}$ OUES thus represents the absolute rate of increase in $\dot{\mathrm{V}}_{\mathrm{O}_{2}}$ per 10-fold increase of $\dot{\mathrm{V}}_{\mathrm{E}}$. HRR (in beats/ min) was defined as the reduction of the heart rate at the peak exercise level compared to the rate 1 min after the cessation of exercise. ${ }^{22}$

\section{Dyspnea and Muscle Fatigue}

Daily living activity-related dyspnea was evaluated with the Italian version of the 5-point Medical Research Council scale modified by the American Thoracic Society. ${ }^{23}$ Dyspnea and muscle fatigue induced by CPET were measured at the end of the incremental exercise by a visual analog scale (VAS). The VAS scale consisted of a 100-mm horizontal line with the word "none" placed at the left end of the scale and the words "very severe" placed at the right of the scale. The VAS scored from 0 to 100 , but the subjects were unaware of the numbers. VAS dyspnea rating $\left(\mathrm{VAS}_{\mathrm{dys}}\right)$ and VAS muscle fatigue rating $\left(\mathrm{VAS}_{\mathrm{fat}}\right)$ were then divided by the maximal work load (ie, $\mathrm{VAS}_{\mathrm{dys}}$ and $\mathrm{VAS}_{\text {fat }}$, respectively, in $\mathrm{mm} /$ watt)..$^{24}$

\section{Body Composition}

Body height and weight were measured anthropometrically. Body composition was assessed by a bioelectrical impedance analysis (BIA) method that is based on the conductance of an electrical sinusoidal alternating current through body fluids. BIA measures the impedance or resistance to the signal as it travels through the water that is found in muscle and fat. Foot-to-foot BIA was measured using a body composition analyzer (model SC-331S, Tanita, Tokyo, Japan). Patients were measured in the standing position with bare feet on the analyzer footpads. The algorithms used to estimate lean body mass from impedance are those given by Segal et al. ${ }^{25}$ The FFM was standardized for height similar to body mass index (BMI): FFM index (FFMI; FFM/height squared, in kilograms per square meter).

\section{Statistical Analysis}

This is a pilot cross-sectional study. Due to the explorative nature of the study no formal sample size calculation was performed. Data are reported as the mean $\pm \mathrm{SD}$, unless otherwise specified. The distribution of variables was assessed by means of Kolmogorov-Smirnov goodness-of-fit test. Relationships between variables were assessed by the Pearson correlation coefficient $(r)$ and linear regression analysis. Comparisons between variables were determined by unpaired $t$ test and chi-square test, when appropriate.

For analysis purposes the population sample was divided into depleted and nondepleted patients, according to the FFMI value. The cutoff values were 14.6 and 16.7 $\mathrm{kg} / \mathrm{m}^{2}$, respectively, for women and men. ${ }^{26}$ According to the IC/TLC at peak of exercise and to peak $\mathrm{O}_{2}$ pulse values, patients in both groups were also divided into 2 categories: patients with IC/TLC $\leq 0.25$ or $>0.25$, and patients with peak $\mathrm{O}_{2}$ pulse $<10$ or $\geq 10 \mathrm{~mL} /$ beats/min, 


\section{Low Fat-Free Mass and Response to Exercise in Patients With COPD}

Table 1. Demographic and Baseline Characteristics of COPD Patients

\begin{tabular}{|c|c|c|c|c|}
\hline & $\begin{array}{l}\text { All Patients } \\
(n=57)\end{array}$ & $\begin{array}{l}\text { Depleted } \\
(n=14)\end{array}$ & $\begin{array}{l}\text { Non-Depleted } \\
\quad(n=43)\end{array}$ & $P^{*}$ \\
\hline Age (y) & $65 \pm 8$ & $67 \pm 8$ & $65 \pm 8$ & .44 \\
\hline Females/Males & $16 / 41$ & $6 / 8$ & $10 / 33$ & .16 \\
\hline BMI $\left(\mathrm{kg} / \mathrm{m}^{2}\right)$ & $25 \pm 3$ & $21 \pm 2$ & $26 \pm 3$ & .001 \\
\hline MRC (0-4) & $1(0-4)$ & $1(0-4)$ & $1(0-4)$ & .99 \\
\hline TLC (\% pred) & $120 \pm 24$ & $119 \pm 21$ & $120 \pm 25$ & .89 \\
\hline $\mathrm{FEV}_{1}(\%$ pred $)$ & $51 \pm 16$ & $48 \pm 16$ & $52 \pm 16$ & .39 \\
\hline $\mathrm{FEV}_{1} / \mathrm{VC}$ & $0.52 \pm 0.11$ & $0.54 \pm 0.09$ & $0.51 \pm 0.11$ & .39 \\
\hline IC/TLC & $0.31 \pm 0.09$ & $0.28 \pm 0.11$ & $0.32 \pm 0.09$ & .18 \\
\hline $\mathrm{FEF}_{50} / \mathrm{FIF}_{50}$ & $0.33 \pm 0.21$ & $0.33 \pm 0.21$ & $0.32 \pm 0.22$ & .89 \\
\hline $\mathrm{D}_{\mathrm{LCO}}(\%$ pred $)$ & $60 \pm 19$ & $52 \pm 17$ & $63 \pm 20$ & .09 \\
\hline $\begin{array}{l}\text { *P: depleted patients } \\
\text { Values are expressed } \\
\mathrm{BMI}=\text { body mass in } \\
\mathrm{TLC}=\text { total lung cap } \\
\mathrm{MRC}=\text { Medical Res } \\
\mathrm{VC}=\text { vital capacity } \\
\mathrm{IC}=\text { inspiratory cap } \\
\mathrm{FEF}_{50}=\text { forced expir } \\
\mathrm{FIF}_{50}=\text { forced inspir } \\
\mathrm{D}_{\mathrm{LCO}}=\text { diffusing ca }\end{array}$ & $\begin{array}{l}\text { son-depleted pati } \\
\text { mean } \pm \text { SD, med } \\
\text { x } \\
\text { ity } \\
\text { rch Council } \\
\text { ty } \\
\text { ory flow measured } \\
\text { ory flow measured } \\
\text { ity of the lung for }\end{array}$ & $\begin{array}{l}50 \% \text { of FVC } \\
50 \% \text { of FVC } \\
\text { arbon monoxide }\end{array}$ & & \\
\hline
\end{tabular}

respectively. The patients with an IC/TLC at the peak of exercise of $\leq 0.25$ may be defined as "heavy hyperinflators." ${ }_{5,6}$ On the basis of the age of our population sample, a value of $10 \mathrm{~mL} / \mathrm{kg} / \mathrm{min}$ may be considered as a threshold value of normality for the peak $\mathrm{O}_{2}$ pulse. ${ }^{27}$

A $P$ value of $<.05$ was taken as significant.

\section{Results}

Seventy-four consecutive stable COPD patients (19 females) between 42 and 75 y of age were screened. Seventeen patients were excluded because of a BMI $>30 \mathrm{~kg} /$ $\mathrm{m}^{2}$. Demographic and clinical characteristics of the 57 patients included in the study are shown in Table 1. At study entry, patients were receiving regular therapy with inhaled steroids (65\%), long-acting $\beta_{2}$ agonists (63\%) and tiotropium $(51 \%)$. All of the patients were ex-smokers. Among them there were wide ranges of air-flow obstruction $\left(\mathrm{FEV}_{1} / \mathrm{VC} 30-69 \%\right)$, lung hyperinflation (IC/TLC $0.10-0.56)$, airway collapsibility $\left(\mathrm{FEF}_{50} / \mathrm{FIF}_{50} 0.07-0.93\right)$, $\mathrm{D}_{\text {LCo }}(21-106 \%)$, and daily living activity-related dyspnea (Medical Research Council scale score 0-4) were found.

Thirty-one ( 8 females) of 57 patients (54\%) experienced arterial hypertension and were receiving therapy with diuretics $(42 \%)$, angiotensin-converting enzyme inhibitors (30\%), $\beta$-blockers (25\%), calcium antagonists $(14 \%)$, and sartans $(5 \%)$. The prevalence of arterial hypertension was not different between depleted and nondepleted patients (50\% vs 56\%). Additionally, the percentage of patients
Table 2. Exercise Characteristics of COPD Patients

\begin{tabular}{|c|c|c|c|c|}
\hline & $\begin{array}{l}\text { All Patients } \\
\quad(n=57)\end{array}$ & $\begin{array}{l}\text { Depleted } \\
(n=14)\end{array}$ & $\begin{array}{l}\text { Non-Depleted } \\
\quad(n=43)\end{array}$ & $P^{*}$ \\
\hline Peak $\dot{\mathrm{V}}_{\mathrm{O}_{2}}(\mathrm{~mL} / \mathrm{min})$ & $1,150 \pm 397$ & $942 \pm 258$ & $1,218 \pm 413$ & .02 \\
\hline $\mathrm{AT}(\mathrm{mL} / \mathrm{min})$ & $819 \pm 258$ & $667 \pm 151$ & $868 \pm 268$ & .003 \\
\hline $\begin{array}{l}\text { Peak workload } \\
\text { (watts) }\end{array}$ & $83 \pm 38$ & $68 \pm 30$ & $88 \pm 39$ & .08 \\
\hline$\dot{\mathrm{V}}_{\mathrm{E}}(\mathrm{mL} / \mathrm{min})$ & $42 \pm 14$ & $38 \pm 12$ & $43 \pm 14$ & .23 \\
\hline$\dot{\mathrm{V}}_{\mathrm{E}} / \mathrm{V}_{\mathrm{CO}_{2}}(\mathrm{~L})$ & $31 \pm 9$ & $32 \pm 9$ & $31 \pm 9$ & .77 \\
\hline Peak IC/TLC & $0.25 \pm 0.1$ & $0.24 \pm 0.1$ & $0.26 \pm 0.1$ & .50 \\
\hline $\begin{array}{l}\text { Rest } \mathrm{O}_{2} \text { pulse } \\
\quad(\mathrm{mL} / \text { beats/min })\end{array}$ & $3.6 \pm 1.3$ & $2.74 \pm 1.3$ & $3.89 \pm 0.8$ & .004 \\
\hline $\begin{array}{l}\text { Peak } \mathrm{O}_{2} \text { pulse } \\
\quad(\mathrm{mL} / \mathrm{beats} / \mathrm{min})\end{array}$ & $9.5 \pm 3.1$ & $7.6 \pm 2.4$ & $10.1 \pm 3.0$ & .006 \\
\hline OUES (mL/min) & $1,421 \pm 516$ & $1,065 \pm 323$ & $1,537 \pm 516$ & .002 \\
\hline HRR (beats/min) & $12.9 \pm 10$ & $8.7 \pm 6$ & $14.4 \pm 11$ & .02 \\
\hline $\mathrm{VAS}_{\mathrm{dys}}(\mathrm{mm} / \mathrm{watts})$ & $1.22 \pm 0.79$ & $1.46 \pm 1.2$ & $1.14 \pm 0.62$ & .20 \\
\hline $\mathrm{VAS}_{\mathrm{fat}}(\mathrm{mm} / \mathrm{watts})$ & $1.16 \pm 0.62$ & $1.59 \pm 0.83$ & $1.01 \pm 0.47$ & .03 \\
\hline $\begin{array}{l}* P \text { : depleted patients vs no } \\
\text { Values are expressed as me } \\
\dot{\mathrm{V}}_{\mathrm{O}_{2}}=\text { oxygen uptake } \\
\mathrm{AT}=\text { anaerobic threshold } \\
\dot{\mathrm{VE}}=\text { minute ventilation } \\
\dot{\mathrm{V}}_{\mathrm{CO}_{2}} \text { carbon dioxide produ } \\
\mathrm{O}_{2} \text { pulse }=\text { peak oxygen p } \\
\mathrm{IC}=\text { inspiratory capacity } \\
\mathrm{TLC}=\text { total lung capacity } \\
\mathrm{OUES}=\text { oxygen uptake ef } \\
\mathrm{HRR}=\text { heart rate recovery } \\
\mathrm{VAS}_{\text {dys }}=\text { visual analog sc } \\
\mathrm{VAS}_{\text {fat }}=\text { visual analog sca }\end{array}$ & $\begin{array}{l}\text { ficiency slope } \\
\text { ale dyspnea rating } \\
\text { le muscle fatique ra }\end{array}$ & & & \\
\hline
\end{tabular}

receiving $\beta$-blockers was not different between depleted and nondepleted patients (29\% vs $23 \%$ ).

Body composition varied consistently (FFMI 12.9-21.3 $\mathrm{kg} / \mathrm{m}^{2}$ ), and, as expected, females had significantly significantly lower FFMI $\left(15.1 \pm 1.6\right.$ vs $18.3 \pm 1.7 \mathrm{~kg} / \mathrm{m}^{2}$, respectively, $P<.001)$. According to the FFMI, 14 of 57 patients $(24.5 \%)$ were categorized as depleted (mean \pm SD FFMI $15.0 \pm 1.4 \mathrm{~kg} / \mathrm{m}^{2}$ ), whereas 43 were nondepleted (FFMI $18.1 \pm 1.8 \mathrm{~kg} / \mathrm{m}^{2}$ ). No significant differences in gender, age, and any lung function parameter at rest were recorded between the 2 groups (Table 1).

All of the included patients completed the exercise test without any complication. Mean peak work load and peak $\dot{\mathrm{V}}_{\mathrm{O}_{2}}$ values were $83 \pm 38$ watt and 1,150 $\pm 397 \mathrm{~mL} / \mathrm{min}$, respectively. Exercise data are summarized in Table 2 . The 2 groups of patients significantly differed $(P<.05)$ in terms of peak $\dot{\mathrm{V}}_{\mathrm{O}_{2}}$ and AT, and in terms of cardiovascular but not ventilatory parameters during exercise. Notably the IC/TLC at peak of exercise was $0.24 \pm 0.1$ and $0.26 \pm 0.1$, respectively, in depleted and in nondepleted patients $(P=0.50)$ (Fig. 1), being $\leq 0.25$ in 9 of $14(64 \%)$ depleted patients and in 23 of $43(53 \%)$ nondepleted patients $(P=0.50)$ (Fig. 2). On the other hand, the peak $\mathrm{O}_{2}$ pulse was $7.6 \pm 2.4$ and $10.1 \pm 3.0 \mathrm{~mL} /$ beats $/ \mathrm{min}$, respectively, in depleted and in nondepleted patients $(P=.006)$, being 

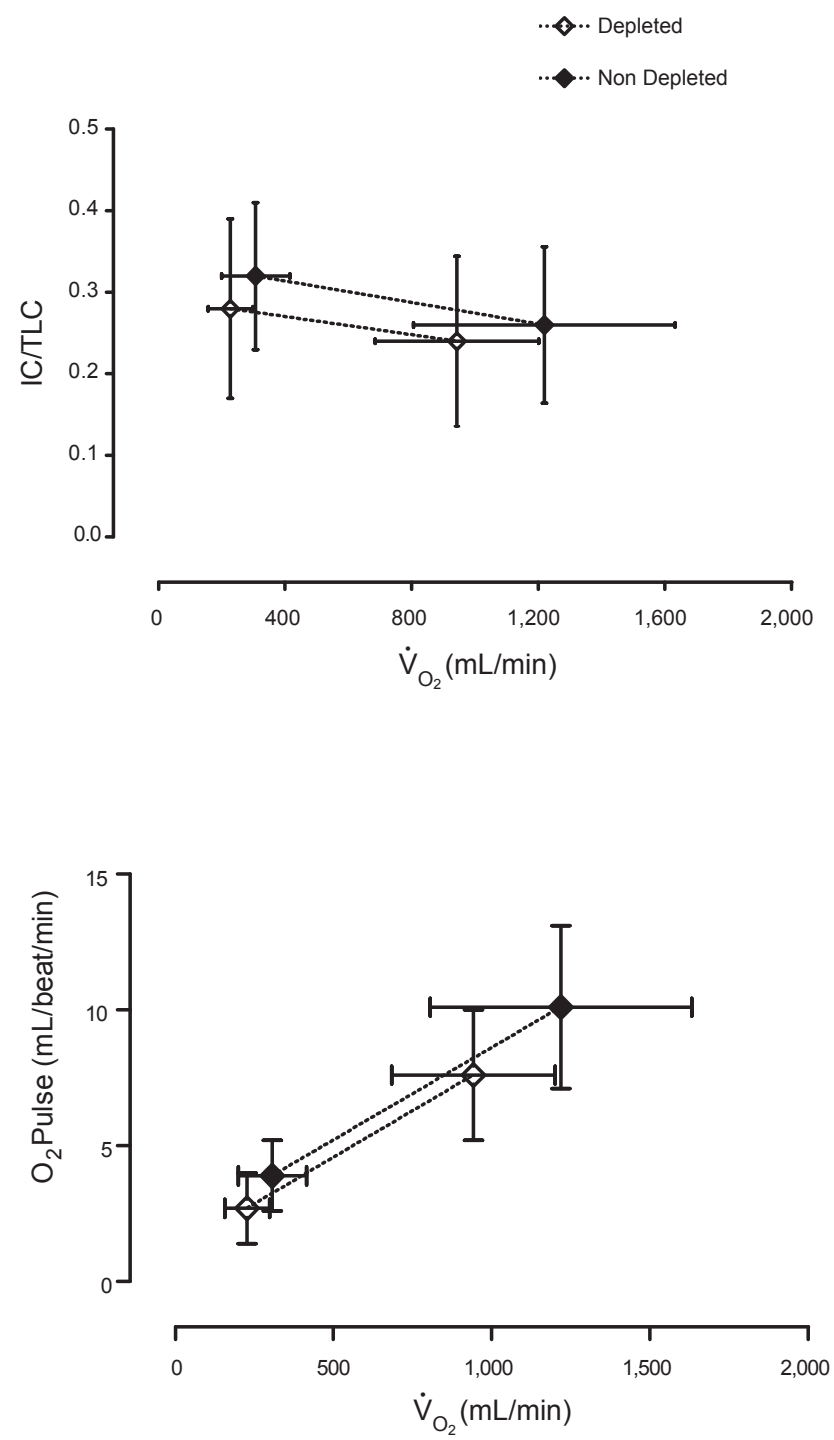

Fig. 1. Mean and SD values of inspiratory capacity (IC)/total lung capacity (TLC) (top) and peak oxygen pulse $\left(\mathrm{O}_{2}\right.$ pulse) (bottom) in relation to the corresponding rest and peak oxygen uptake $\left(\dot{\mathrm{V}}_{\mathrm{O}_{2}}\right)$ values in depleted and nondepleted COPD patients. No difference was found between depleted and nondepleted patients when IC/ TLC values were considered both at rest and at peak $\dot{V}_{\mathrm{O}_{2}}$ values. $\mathrm{O}_{2}$ pulse values were significantly lower both at rest $(P=.004)$ and at peak $(P=.006)$ of $\dot{\mathrm{V}}_{\mathrm{O}_{2}}$ values in depleted compared with nondepleted patients.

$\geq 10 \mathrm{~mL} / \mathrm{beats} / \mathrm{min}$ in 3 of $14(21 \%)$ depleted patients and in 23 of $43(53 \%)$ nondepleted patients $(P=.04)$ (see Fig. $2)$. The 2 categories of patients were different in $\mathrm{VAS}_{\mathrm{fat}}$, but not in $\mathrm{VAS}_{\mathrm{dys}}$.

Dynamic hyperinflation developed in 10 of the 14 depleted patients (mean age $66 \pm 9 \mathrm{y}, 3$ females) and in 36 of the 43 nondepleted patients (mean age $65 \pm 8 \mathrm{y}, 10$ females) (decline in IC greater than zero). When hyperinflators were considered, again depleted and nondepleted patients were not different in resting air-flow obstruction
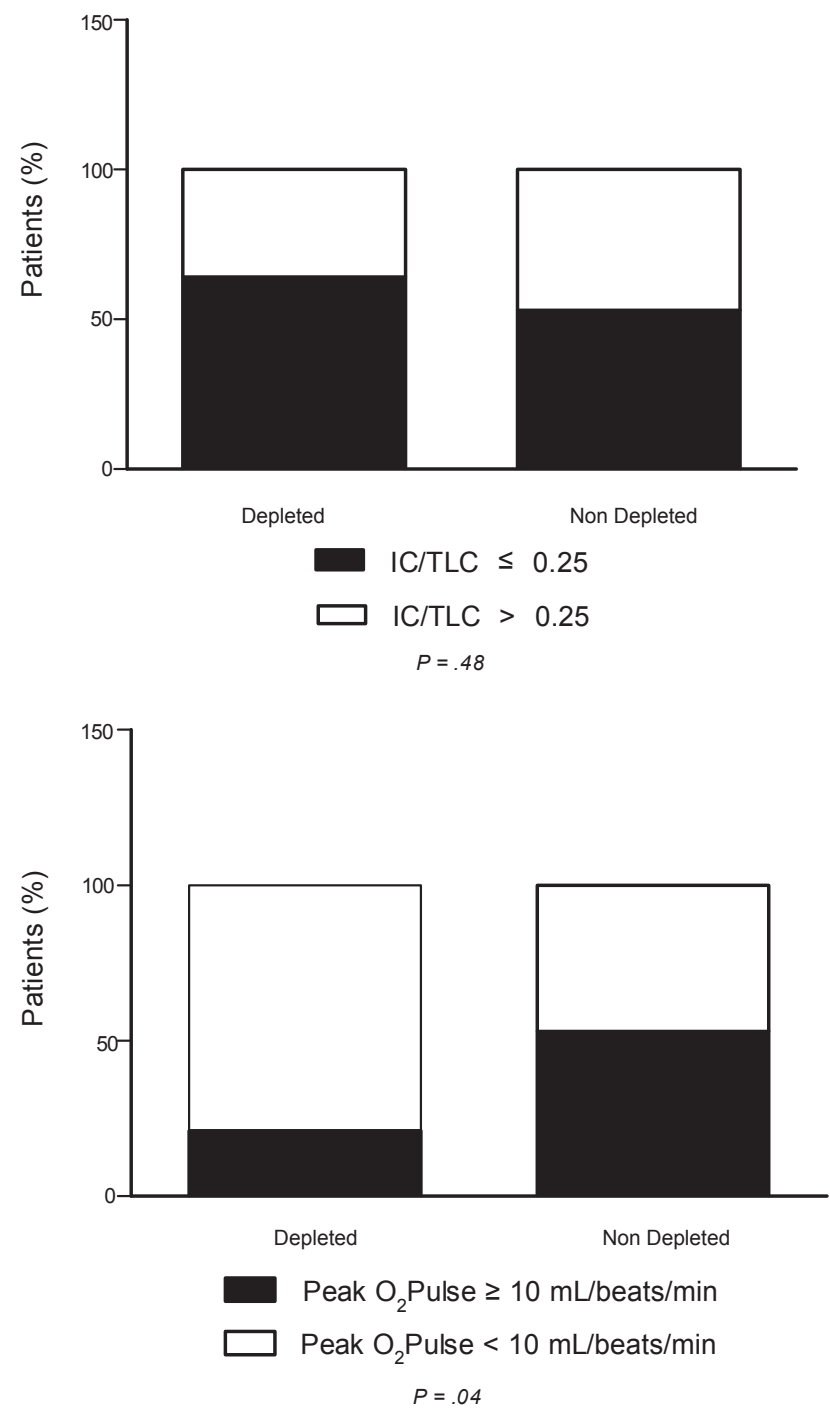

Fig. 2. Percentage of COPD patients categorized by fat-free mass index (FFMI) and by inspiratory capacity (IC)/total lung capacity (TLC) (top) and by FFMI and peak oxygen pulse $\left(\mathrm{O}_{2}\right.$ pulse) (bottom). The ratio between the number of patients with IC/TLC $\leq 0.25$ and that of patients with IC/TLC $>0.25$ was not different in depleted patients compared with nondepleted patients (9 of 14 vs 23 of 20; $P=.50)$. On the contrary, the ratio between the number of patients with peak $\mathrm{O}_{2}$ pulse $\geq 10 \mathrm{~mL} /$ beats $/ \mathrm{min}$ and that of patients with peak $\mathrm{O}_{2}$ pulse $<10 \mathrm{~mL} /$ beats/min was significantly lower in depleted patients compared with nondepleted patients ( 3 of 11 vs 23 of $20 ; P=.04$ ).

$\left(\mathrm{FEV}_{1} / \mathrm{VC} 0.50 \pm 0.08\right.$ vs $\left.0.50 \pm 0.11, P=.95\right)$, lung hyperinflation (IC/TLC $0.28 \pm 0.12$ vs $0.33 \pm 0.09$, $P=.17)$, and airway collapsibility $\left(\mathrm{FEF}_{50} / \mathrm{FIF}_{50}\right.$ $0.26 \pm 0.11$ vs $0.31 \pm 0.20, P=.43$ ) as well as in dynamic hyperinflation during exercise (peak IC/TLC $0.22 \pm 0.09$ vs $0.26 \pm 0.09, P=.22$ ) and in $\mathrm{VAS}_{\mathrm{dys}}$ $(1.51 \pm 1.4 \mathrm{vs} 1.16 \mathrm{~mm} / \mathrm{W} \pm 0.56, P=.23)$. On the other hand, they significantly differed in peak $\dot{\mathrm{V}}_{\mathrm{O}_{2}}(897 \pm 213$ vs $1,182 \pm 356 \mathrm{~mL} / \mathrm{min}, P=.03)$, in peak $\mathrm{O}_{2}$ pulse 
(7.3 \pm 2.1 vs $9.8 \pm 2.7 \mathrm{~mL} / \mathrm{beats} / \mathrm{min}, P=.009)$, OUES $(1,033 \pm 334$ vs $1,519 \pm 512 \mathrm{~mL} / \mathrm{min}, P=.007)$, HRR $(7.5 \pm 5.1 \mathrm{vs} 15.0 \pm 11.0 \mathrm{~mL} / \mathrm{min}, P=.04)$, and $\mathrm{VAS}_{\text {fat }}$ $(1.55 \pm 0.8$ vs $.99 \pm 0.44 \mathrm{~mm} / \mathrm{W}, P=.005)$.

In all patients, significant correlations were found between FFMI and peak $\mathrm{O}_{2}$ pulse $(r=0.64, P=.001)$, peak $\dot{\mathrm{V}}_{\mathrm{O}_{2}}(r=0.587, P=.001)$, OUES $(r=0.527, P=.001)$, peak work load $(r=0.51, P=.001)$, and $\mathrm{VAS}_{\text {fat }}(r$ $=-0.44, P=.001)$ (Fig. 3).

\section{Discussion}

The main finding of this study is that COPD patients with low FFM, compared with nondepleted patients, may show significantly lower exercise tolerance for a given and similar level of resting and dynamic lung hyperinflation on exertion. This finding supports the view that FFM depletion plays a significant part in the reduction of exercise capacity, irrespective of ventilatory constraints in the COPD population. In addition, the FFM depletion is strictly associated with poor cardiovascular response to exercise and to leg fatigue but not to dyspnea on exertion.

In the present study, we found that one-fourth of COPD patients across Global Initiative for Chronic Obstructive Lung Disease stages and who are in stable clinical condition present with a depletion of lean body mass. Malnutrition is a common finding in COPD patients, and the estimate of its prevalence may vary depending on the characteristics of the study population. In a large cohort of COPD patients, Schols et al ${ }^{28}$ showed that depletion of body weight was present in $40-50 \%$ of patients with chronic hypoxemia or severe air-flow obstruction and in $25 \%$ of patients with moderate air-flow limitation. More recently, the prevalence of low BMI as well as low FFMI was found to be significantly higher in female than in male COPD patients, whereas no differences in $\mathrm{FEV}_{1}$, dyspnea score, and health status were observed between depleted and nondepleted COPD patients. ${ }^{29}$ The reduction in body weight and FFM in COPD patients is mainly ascribed to a disturbed energy balance, since it has been shown that these patients may exhibit an increased daily energy expenditure compared with healthy subjects. ${ }^{30} \mathrm{It}$ is not yet clear whether malnutrition in people with COPD is the cause of their deterioration or just part of the progress of the disease ${ }^{31}$; in any case it may be only partially reversed by nutritional supplementation. ${ }^{32}$

The results of this study are in line with those of previous reports showing that body weight depletion is related to a decreased exercise performance in COPD patients. ${ }^{8-12}$ Our patients with low FFM showed a significant reduction in aerobic capacity both at peak of exercise and at AT. In our study, depleted and nondepleted patients did not differ in both resting spirometry and lung volume measurements and in operational volumes measured during
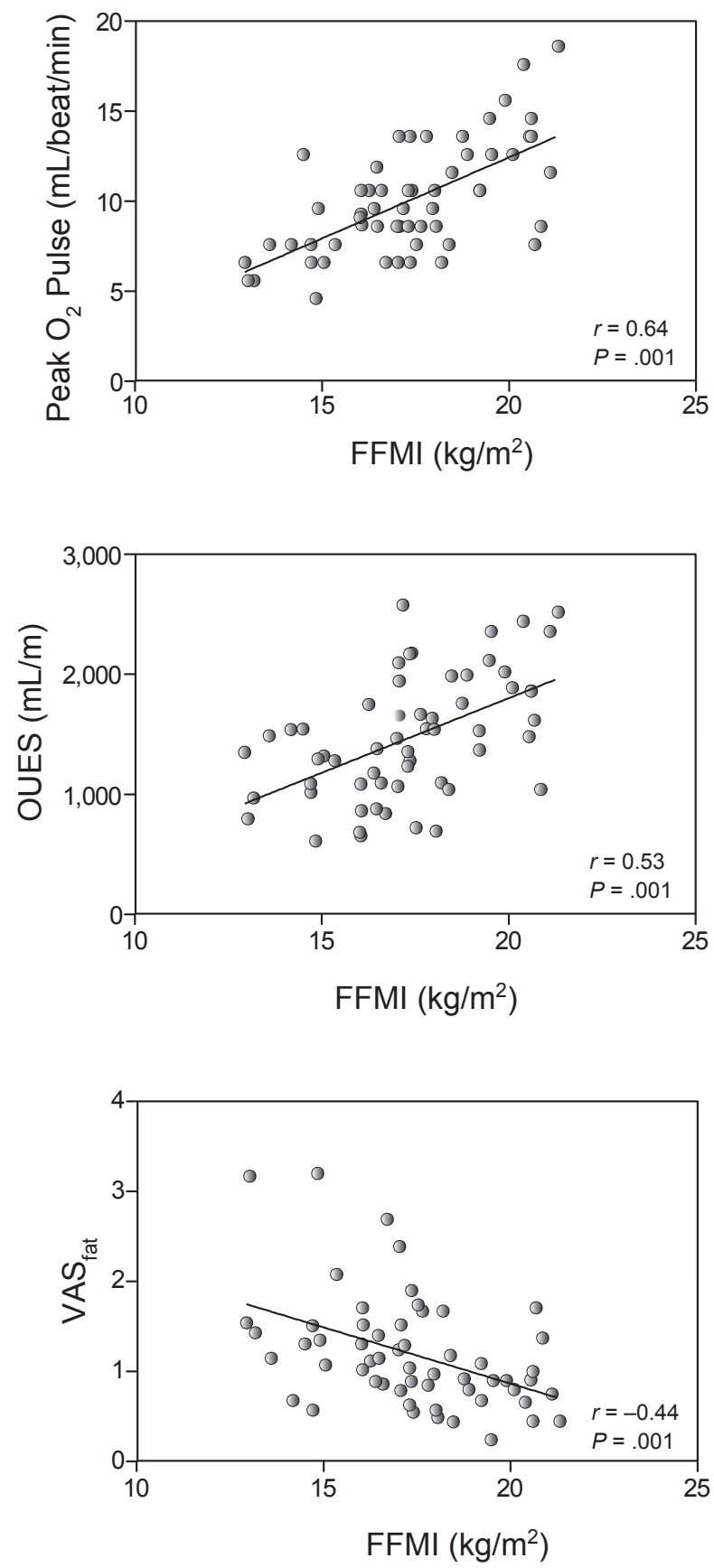

Fig. 3. Relationship between fat-free mass index (FFMI) and peak oxygen pulse $\left(\mathrm{O}_{2}\right.$ pulse) (top), oxygen uptake efficiency slope (OUES) (middle), and leg fatigue (bottom) in 57 COPD patients. $\mathrm{VAS}_{\text {fat }}=$ visual analog scale muscle fatigue rating.

maximal exercise. The 2 groups of patients were also not different in breathlessness perception, but they differed in leg fatigue at peak of exercise. It is conceivable to assume that the same degree of dynamic hyperinflation and the lower FFM may on the one hand explain the same degree of exertional dyspnea, and on the other hand the greater 


\section{Low Fat-Free Mass and Response to Exercise in Patients With COPD}

leg fatigue in the depleted patients compared with nondepleted patients.

Different from our results, earlier studies reported a blunted ventilatory response at maximal exercise in depleted patients with COPD. ${ }^{10,12}$ Notably, Palange et al ${ }^{10}$ showed that patients with a lower body weight had higher dead space/ $\mathrm{V}_{\mathrm{T}}$ when cycling. Moreover, Baarends et al ${ }^{12}$ showed that patients with low FFM had an impaired ability to increase the $\mathrm{V}_{\mathrm{T}}$ during exercise. These findings were explained by a greater degree of dynamic hyperinflation on exertion that would likely have been borne by the malnourished COPD patients, although in none of these studies were the operational volumes during exercise assessed. It is noteworthy that in these 2 studies $^{10,12}$ the depleted patients differed in resting lung function and that a blunted response of $\mathrm{V}_{\mathrm{T}}$ at peak of exercise also could have been explained by the weakness of respiratory muscle as is found in malnourished COPD patients. ${ }^{33,34}$ This was not the case in our study population.

In our study, a poor cardiovascular response to exercise was strictly associated with the FFM below the cutoff values. A poor cardiovascular response to exercise was related to dynamic hyperinflation on exertion in patients with severe COPD, ${ }^{5}$ and this finding has been recently confirmed and extended by our group in patients with a wide range of air-flow obstruction. ${ }^{6}$ In the present series, the depleted patients, compared with nondepleted patients, significantly differed in cardiovascular response to exercise, for a given level of hyperinflation at rest and on exertion, indicating that a low FFM may independently affect cardiovascular function. Indeed, both resting and peak $\mathrm{O}_{2}$ pulse values were significantly lower in depleted patients compared with nondepleted patients, whereas peak $\mathrm{O}_{2}$ pulse strongly related to FFM in the whole population. The $\mathrm{O}_{2}$ pulse may be considered as a reliable surrogate marker of the stroke volume. ${ }^{19}$ In healthy subjects, exercise stroke volume may be estimated simply as 5 times the slope of the linear $\dot{\mathrm{V}}_{\mathrm{O}_{2}}$-heart rate relationship. ${ }^{35}$

We also found that depleted and nondepleted patients differed in 2 other noninvasive parameters of cardiovascular response to exercise, such as OUES and HRR. OUES values were significantly lower in depleted patients and strongly related to FFM in all patients. The OUES represents the rate of increase of $\dot{\mathrm{V}}_{\mathrm{O}_{2}}$ in response to a given $\dot{\mathrm{V}}_{\mathrm{E}}$ during incremental exercise, indicating how effectively oxygen is extracted and taken into the body ${ }^{36}$; it is considered as an objective measure of cardiorespiratory and muscular fitness. ${ }^{37}$ Last, HRR, a marker of the cardiac autonomic function and a powerful predictor of mortality in the general population, ${ }^{22}$ was significantly lower in our depleted patients ( 8.7 beats/min on average). It is of note that a value of $\leq 12$ beats/min is considered to be abnormal, ${ }^{22}$ and a low HRR was associated with a decreased survival time even in the COPD population. ${ }^{38}$
It is conventionally assumed that the skeletal muscle pump is crucial in the local and systemic circulatory effects following exercise. ${ }^{39}$ By expulsing the peripheral venous blood volume during exercise, the muscle pump may enhance venous return, central venous pressure, end-diastolic volume, and thus stoke volume and cardiac output. ${ }^{39}$ In this way, the muscle pump also makes more blood flow available to be diverted to active muscle, thereby indirectly inducing muscle hyperemia. ${ }^{39}$ Muscle blood vessels are in turn tethered to the surrounding muscle, thereby ensuring that muscle mechanical factors are transmitted to the vasculature. ${ }^{40}$ Accordingly, skeletal muscle depletion may negatively affect the cardiovascular response to exercise. The present study further strengthens this conclusion.

In summary, low FFM is one important determinant of exercise tolerance, accomplished by impairing the cardiovascular response in patients with COPD, irrespective of ventilatory constraints on exertion. This finding may have some indirect clinical implications. It is conceivable that during the course of rehabilitation, malnourished COPD patients might present with an impaired cardiovascular response to exercise, thereby worsening the impact on their disability. Further studies should be able to address this matter and to find possible solutions.

\section{REFERENCES}

1. Pitta F, Troosters T, Spruit MA, Probst VS, Decramer M, Gosselink R. Characteristics of physical activities in daily life in chronic obstructive pulmonary disease. Am J Respir Crit Care Med 2005;171(9): 972-977.

2. O'Donnell DE. Dynamic hyperinflation and its clinical implication in COPD. Rev Mal Respir 2008;25(10):1305-1318.

3. Garcia-Rio F, Lores V, Mediano O, Rojo B, Hernanz A, LópezCollazo E, et al. Daily physical activity in patients with chronic obstructive pulmonary disease is mainly associated with dynamic hyperinflation. Am J Respir Crit Care Med 2009;180(6):506-512.

4. O'Donnell DE. Hyperinflation, dyspnea, and exercise intolerance in chronic obstructive pulmonary disease. Proc Am Thorac Soc 2006; 3(2):180-184.

5. Vassaux C, Torre-Bouscoulet L, Zeineldine S, Cortopassi F, PazDiaz H, Celli BR, et al. Effects of hyperinflation on the oxygen pulse as a marker of cardiac performance in COPD. Eur Respir J 2008; 32(5):1275-1282.

6. Tzani P, Aiello M, Elia D, Boracchia L, Marangio E, Olivieri D, et al. Dynamic hyperinflation is associated with a poor cardiovascular response to exercise in COPD patients. Respir Res 2011;12:150.

7. Kim HC, Mofarrahi M, Hussain SNA. Skeletal muscle dysfunction in patients with chronic obstructive pulmonary disease. Int J Chron Obstruct Pulmon Dis 2008;3(4):637-658.

8. Wilson DO, Rogers RM, Wright EC, Anthonisen NR. Body weight in chronic obstructive disease. Am Rev Respir Dis 1989;139(6): 1435-1438.

9. Gray-Donald K, Gibbons L, Shapiro SH, Macklem PT, Martin JG. Nutritional status and mortality in chronic obstructive pulmonary disease. Am J Respir Crit Care Med 1996;153(3):961-966.

10. Palange P, Forte S, Felli A, Galassetti P, Serra P, Carlone S. Nutritional state and exercise tolerance in patients with COPD. Chest 1995;107(5):1206-1212. 


\section{Low Fat-Free Mass and Response to Exercise in Patients With COPD}

11. Schols AM, Mostert R, Soeters PB, Wouters EF. Body composition and exercise performance in patients with chronic obstructive pulmonary disease. Thorax 1991;46(10):695-699.

12. Baarends EM, Schols AMWJ, Mostert R, Wouters EFM. Peak exercise response in relation to tissue depletion in patients with chronic obstructive pulmonary disease. Eur Respir J 1997;10(12):2807-2813.

13. Pauwels RA, Buist AS, Calverley PM, Jenkins CR, Hurd SS, GOLD Scientific Committee. Global strategy for the diagnosis, management, and prevention of chronic obstructive pulmonary disease. NHLBI/WHO Global Initiative for Chronic Obstructive Lung Disease (GOLD) Workshop summary. Am J Respir Crit Care Med 2001;163(5):1256-1276.

14. Miller MR, Hankinson J, Brusasco V, Burgos F, Casaburi R, Coates A, et al. ATS/ERS Task Force Standardisation of spirometry. Eur Respir J 2005;26(2):319-338.

15. Wanger J, Clausen JL, Coates A, Pedersen OF, Brusasco V, Burgos F, et al. Standardisation of the measurement of lung volumes. Eur Respir J 2005;26(3):511-522.

16. Quanjer PH, Tammeling GJ, Cotes JE, Pedersen OF, Peslin R, Yernault JC. Lung volumes and forced ventilatory flows. Report Working Party Standardization of Lung Function Tests, European Community for Steel and Coal. Official Statement of the European Respiratory Society. Eur Respir J Suppl 1993;16:5-40.

17. Cotes JE, Chinn DJ, Quanjer PH, Roca J, Yernault JC. Standardization of the measurement of transfer factor (diffusing capacity). Report Working Party Standardization of Lung Function Tests, European Community for Steel and Coal Official Statement of the European Respiratory Society. Eur Respir J Suppl 1993;16:41-52.

18. American Thoracic Society, American College of Chest Physicians. Statement on cardiopulmonary exercise testing. Am J Respir Crit Care Med 2003;167(2):211-277.

19. Stubbing DG, Pengelly LD, Morse JL, Jones NL. Pulmonary mechanics during exercise in subjects with chronic airflow obstruction. J Appl Physiol 1980;49(3):511-515.

20. Zafar MA, Tsuang W, Lach L, Eschenbacher W, Panos RJ. Dynamic hyperinflation correlates with exertional oxygen desaturation in patients with chronic obstructive pulmonary disease. Lung 2013;191(2): 177-182.

21. Baba R, Nagashima M, Goto M, Nagano Y, Yokota M, Tauchi N, et al. Oxygen uptake efficiency slope: a new index of cardiorespiratory functional reserve derived from the relation between oxygen uptake and minute ventilation during incremental exercise. J Am Coll Cardiol 1996;28(6):1567-1572.

22. Cole CR, Blackstone EH, Pashkow FJ, Snader CE, Lauer MS. Heartrate recovery immediately after exercise as a predictor of mortality. N Engl J Med 1999;341(18):1351-1357.

23. Brooks SM. Surveillance for respiratory hazards. ATS News 1982; 8:12-16.

24. Tzani P, Piepoli MF, Longo F, Aiello M, Serra W, Maurizio AR, et al. Resting lung function in the assessment of the exercise capacity in patients with chronic heart failure. Am J Med Sci 2010;339(3): 210-215.
25. Segal KR, Van Loan M, Fitzgerald PI, Hogdon JA, Van Itallie TB. Lean body mass estimation by bioelectrical impedance analysis: a four-site cross-validation study. Am J Clin Nutr 1988;47(1):7-14.

26. Kyle UG, Y Schutz, Dupertuis YM, Pichard C. Body composition interpretation: contributions of the fat-free mass index and the body fat mass index. Nutrition 2003;19(7-8):597-604.

27. Wasserman K, Hansen JE, Sue DY, Stringer WW, Sietsema KE, Sun $\mathrm{X}-\mathrm{G}$, et al. Normal values. In: Principles of exercise testing and interpretation. Philadelphia: Lippincott Williams \& Wilkins;1994: 143-162.

28. Schols AMW, Soeters PB, Dingemans AMC, Mostert R, Frantzen PJ, Wouters EFM. Prevalence and characteristics of nutritional depletion in patients with stable COPD eligible for pulmonary rehabilitation. Am Rev Respir Dis 1993;147(5):1151-1156.

29. Vermeeren MA, Creutzberg EC, Schols AM, Postma DS, Pieters WR, Roldaan AC, et al. Prevalence of nutritional depletion in a large out-patient population of patients with COPD. Respir Med 2006; 100(8):1349-1355.

30. Crisafulli E, Costi S, Clini EM. Anthropometry as measure of risk in COPD patients. In: Preedy VR, editor. Handbook on anthropometry: physical measures of human form in health and disease. Berlin: Springer Science+Business Media LLC;2012:2357-2371.

31. Collins PF, Stratton RJ, Elia M. Nutritional support in chronic obstructive pulmonary disease: a systematic review and meta-analysis. Am J Clin Nutr 2012;95(6):1385-1395.

32. Baarends EM, Schols AM, Pannemans DL, Westerterp KR, Wouters EF. Total free living energy expenditure in patients with severe chronic obstructive pulmonary disease. Am J Respir Crit Care Med 1997;155(2):549-554.

33. Nishimura $Y$, Tsutsumi $M$, Nakata $H$, Tsunenari $T$, Maeda $H$, Yokoyama M. Relationship between respiratory muscle strength and lean body mass in men with COPD. Chest 1995;107(5):1232-1236.

34. Piitulainen E, Areberg J, Lindén M, Eriksson S, Mattsson S, Wollmer P. Nutritional status and muscle strength in patients with emphysema and severe alpha(1)-antitrypsin deficiency. Chest 2002;122(4):12401246.

35. Whipp BJ, Higgenbotham MB, Cobb FC. Estimating exercise stroke volume from asymptotic oxygen pulse in humans. J Appl Physiol 1996;81(6):2674-2679.

36. Hollenberg M, Tager IB. Oxygen uptake efficiency slope: an index of exercise performance and cardiopulmonary reserve requiring only submaximal exercise. J Am Coll Cardiol 2000;36(1):194-201.

37. Akkerman M, van Brussel M, Hulzebos E, Vanhees L, Helders PJ, Takken T. The oxygen uptake efficiency slope: what do we know? J Cardiopulm Rehabil Prev 2010;30(6):357-373.

38. Lacasse M, Maltais M, Poirier P, Lacasse Y, Marquis K, Jobin J, et al. Post-exercise heart rate recovery and mortality in chronic obstructive pulmonary disease. Respir Med 2005;99(7):877-886.

39. Sheriff D. Point: the muscle pump raises muscle blood flow during locomotion. J Appl Physiol 2005;99(1):371-372.

40. Sheriff DD. Local and reflex regulation of muscle blood flow during dynamic exercise. In: Exercise, nutrition, and environmental stress. Vol. 2. Traverse City, MI: IL Cooper;2002:19-44. 